\title{
OJED
}

Volume 5, Issue 1 (2020), pp. 184-189

International Journal of

Multidisciplinary Perspectives in Higher Education

ISSN: 2474-2546 Print/ ISSN: 2474-2554 Online

https://ojed.org/jimphe

\section{When Extraordinary Circumstances Yield Exceptional Consequences: The Importance of Readiness, Receptiveness, and Responsiveness}

\author{
Nancy P. Gallavan \\ University of Central Arkansas
}

\begin{abstract}
During her last semester prior to retirement, a university professor of teacher education supervised 15 interns enrolled in a preparation program and college department different from the professor's usual program and department due to changes in the college's preparation program student enrollment and faculty availability. The ever-changing, extraordinary circumstances experienced by the interns and supervisor during the 2020 spring semester illuminate the vital responsibilities of readiness to teach, receptiveness to feedback, and responsiveness to expectations (Gallavan \& Merritt, 2018). Established on authentic expressions and exchanges of trust, efficacy, agency, and cultural humility [TEACH], their shared journeys yielded exceptional consequences for both the interns and the supervisor enriched by the supervisor's insights and inspirations as teacher educator, co-constructivist, and instructional coach.
\end{abstract}

Keywords: co-constructivism, internship, instructional coach, readiness, receptiveness, responsiveness, supervision

The 2019 fall semester began my last semester as an educator. Culminating 25 years as a teacher educator and college administrator preceded by 20 years as a classroom teacher and school administrator, 
I felt fully satisfied and fortunately situated for the next, new adventures in my life. My future looked good. Mid-semester, the university announced a retirement incentive for which I was eligible if I delayed my retirement to the 2020 spring semester. The financial package appealed, and my next, new adventures could wait six more months. My future looked even better.

Given my decision to delay retirement, I was unable to teach my usual course load. Understandably, those courses had been reassigned, so I was offered the opportunity to teach different courses in a different program, different department, and different format. After 15 years of teaching graduate K-12 MAT candidates online, I would be supervising undergraduate K-5 elementary education candidates face-to-face during Internship I. Undergraduate elementary education candidates complete their programs as cohorts, interacting primarily with the same faculty and same candidates with whom they have become acquainted during three previous semesters. All courses are conducted face-to-face, and candidates have become accustomed to specific procedures. In the prior semester, candidates, i.e., interns, had been assigned to classrooms to observe one teacher one day per week, ultimately, teaching a small group of students three times. During Internship I, interns visit classrooms 1.5 days per week and will teach five observed lessons among multiple other field-based assignments. Conversely, the MAT candidates I had been teaching for 15 years online were taught by ten different faculty with approximately half of the candidates were teaching in their own classrooms on provisional licenses. I was curious to delve into the differences between the graduate MAT candidates and the undergraduate elementary education candidates.

During my career in education, I have continued to refine a foundation based on three responsibilities that I try to teach, model, and apply to my self-efficacy: readiness to teach, receptiveness to feedback, and responsiveness to expectations (Gallavan \& Merritt, 2018). The capacity to guide and support other people in our lives reciprocated as we listen to and reflect on the guidance and support that we receive from other people equips and empowers us to grow and mature through meaningful transitions. I have discovered that when teachers and learners co-construct expectations, individualization and innovation inspire learners to exceed initial expectations. Everyone benefits significantly by investing first in the people, second in the possibilities, and third in the production. Too often, teaching and learning occur in the reverse order. Relying on my foundation, I began my last semester with the undergraduate elementary education interns as a capstone for my career.

The first few weeks of Internship I, I scheduled time in each intern's classroom facilitating quiet conversations as the intern and I observed the classroom and teacher, partnered with additional, lengthier time spent with 
each intern outside of the classroom processing our classroom observations and the intern's discoveries. Additionally, weekly I met with the five interns placed in each of three elementary schools as a small group to preview expectations, answer questions, and, most importantly, calm uncertainties related to their classroom teaching and course assignments. Through my accessibility and acceptance, the interns and I became comfortable with one another easily and established trusting relationships quickly as we embarked on our shared journeys. Supervision provided me the ideal opportunity to learn from and with teacher candidates through their lived experiences. Indeed, my future looked like the best.

Halfway through the semester, mid-March 2020, our lives changed abruptly and completely due to the pandemic; the interns and I were sent home. University courses transitioned to online platforms, and field experiences had to be reconfigured. More significantly, interns needed comprehensive reassurance supporting them personally, pedagogically, and professionally. I did not anticipate the importance of my foundations of readiness to teach, receptiveness to feedback, and responsiveness to expectations for my interns or for me.

The opportunity to supervise undergraduate elementary education Internship I interns was exciting! As my own mentor in higher education emphasized, I brought years of education, experience, and expertise as an elementary and middle level classroom teacher and as a teacher educator grounded on co-constructivism. I ascribed to Piaget's research that purports learning is actively built on prior knowledge as learners are introduced to and integrate new information (McLeod, 2019) in ways that are developmentally appropriate and relevant; learners are motivated to maintain equilibrium, especially when encountering incoherent or inconsistent information (Proulx, 2006). Overlapping with Piaget's research, I also credit Vygotsky's research that identified the essential role that the sociocultural context plays in the Zone of Proximal Development contributing to the process of meaning making (McLeod, 2019). Purposeful engagement in cognitive equilibrium and sociocultural contexts creates environments of rich and powerful learning individually, among peers, and with the teacher.

Additionally, I am an instructional coach, i.e., "partnering with clients in a thought-provoking and creating process that inspires them to maximize their personal and professional potential" (International Coach Federation, 2020, para 9). Combining co-constructivism with instructional coaching provided an ideal milieu as an intern supervisor to apply the frame I have developed. Labeled TEACH, this frame is an acronym for my basics of learning, living, and lifting others: trust, efficacy, agency, and cultural humility i.e., the "ability to maintain an interpersonal stance that is otheroriented (or open to the other) in relation to aspects of cultural identify that are most important to the person" (Hook et al., 2013; p. 2). Although the 
expectations of Internship I had been written to fulfill the state's teacher excellence support system, integrating TEACH advanced proficiencies previously unknown to or uninvestigated by the interns. First, I modeled each of these constructs as I visited interns individually and in groups; second, I used the words to connect their prior knowledge and experiences with their new knowledge and experiences to pursue equilibrium during our conversations. Third, I emphasized the words bridging their purposes with their practices to ensure meaning making.

Throughout this process, interns appeared to grow, develop, and learn as they reflected on their readiness to teach, receptiveness to feedback, and their responsiveness to expectations. However, initially they seemed surprised when I began using co-constructivist strategies, practicing coaching techniques, and sharing $\mathrm{TEACH}$; they were not accustomed to anyone ensuring them voice, choice, and inclusion during decision-making and helping them recognize their own comfort, confidence, and competence. As one intern candidly shared with me, "No one has treated me as an equal with the freedoms and responsibilities that I should and could be developing as a teacher." Similar comments were echoed by interns, which reassured me that my approaches were effective.

As the semester began, and as the newcomer to the undergraduate elementary education teacher preparation program, I completed each course expectation before introducing the assignment. Immediately, I recognized that the instructions and assessments could be strengthened in clarity, comprehension, and context, so I rewrote instructions and developed detailed rubrics aligned with program instructions and rubrics. I guided the interns with these supplemental documents and integrated the purpose, presence, and power of TEACH. My goal was to immerse interns into a holistic learning experience, mindfully supporting their acceptance of their individual personal characteristics, pedagogical capacities, and professional commitments. Soon, interns' advancements associated with readiness to teach, receptiveness to feedback, and responsiveness to expectations were clearly evident during classroom observations, reflection conversations, and assignment completion. Interns became more assured both in and out of classrooms and were beginning to recognize their own transformations. Successfully, interns completed writing professional growth plans (to be implemented throughout the semester in their classrooms) and teaching their first observed learning experiences.

In mid-March, when interns and I were sent home, the transition to our online experiences began with urgent attention to each intern's comfort, situation, and needs. Within the first few days, I emailed the 15 interns as a group with general information coupled with emailing each intern to schedule Zoom and/or telephone conversations. Committed to continuing the rapport established with each intern was paramount. The energy dedicated to each intern's personal, pedagogical, and professional co- 
constructed knowledge and sociocultural context during the first half of the semester enabled us to expand and enrich both the teaching and the learning in ways that equipped and empowered each intern and for me to glean exceptional consequences from these extraordinary circumstances.

As we navigated the second half of the semester, interns conquered the second observed learning experience (conducted in their homes), wrote their professional growth plan reflections (with modifications), and completed a new assignment that we co-constructed as a group to replace an expectation originally intended to be conducted in their classrooms. Our collaboration in planning and differentiating outcomes to accommodate each intern (Kise, 2017) generated links to and visibility of trust, efficacy, agency, and cultural humility. Transitioning to online teaching and learning augmented the interns' readiness to teach, receptiveness to feedback, and responsiveness to expectations as well as my own learning about teaching with unanticipated discoveries.

During finals week, Internship I supervisors were required to meet with each intern, provide observations, and share evaluations. However, aligned with co-constructivism and coaching, I asked each intern to engage in a shared conversation and describe her greater strengths and lesser strengths (rather than weaknesses) in relationship to the prescribed observation criteria. As each intern self-assessed openly and honestly, collaboratively we delved into the intern's readiness to teach, receptiveness to feedback, and responsiveness to expectations. Through their authentic reflections, all 15 interns confirmed their transformations had exceeded their anticipations both in the classroom and online as they described the values of TEACH for themselves and their K-5 students. Now, as they wait for the 2020 fall semester and Internship II, the interns and I continue to communicate via email and Zoom to nurture their readiness, receptiveness, and responsiveness.

The 2020 spring semester certainly yielded exceptional consequences associated with my newfound readiness through learning, receptiveness through listening, and responsiveness through lifting. The experiences stretched and strengthened my outlook and openness toward possible paths. I am renewed in knowing that my future endeavors will include unique, most likely previously unexplored, opportunities for me to guide, support, and celebrate adults in pursuit of their (and my) own next, new adventures.

\section{References}

Gallavan, N. P., \& Merritt, J. P. (2018). Reinforcing MAT course goals during internship experiences via Author's seven 
essential elements. In Author \& L. G. Putney (Eds.), ATE Yearbook XXVI: Building upon inspirations and inspirations with hope, courage, and strength: Teacher educators' commitment to today's teachers and tomorrow's leaders (pp. 43-62). Rowman \& Littlefield.

Hook, J. N., Davis, D. E., Owen, J., Worthington Jr., E. L., \& Utsey, S. O. (2013). Cultural humility: Measuring openness to culturally diverse clients. Journal of Counseling Psychology, 60 (3), 1-14. http://doi.10.1037/a0032595

International Coach Federation [ICF]. (2020). About ICF. https://coachfederation.org/about

Kise, J. A. G. (2017). Differentiated coaching: A framework for helping educators change. Corwin.

McLeod, S. (2019). Constructivism as a theory for teaching and learning.

Simply

Psychology. https://www.simplypsychology.org/constructivism.html

Proulx, J. (2006). Constructivism: A re-equilibration and clarification of concepts, and some potential implications for teaching and pedagogy.

Radical Pedagogy,

7 , 5. http://radicalpedagogy.icaap/org/content/issue8_1/proulx.html

\section{Author Bio}

NANCY P. GALLAVAN, PhD, is Professor Emerita of Teacher Education in the Department of Teaching and Learning at the University of Central Arkansas. Her major interests lie in the areas of teacher preparation, i.e., classroom assessment, cultural competence, online teaching and learning, and social studies education. Email: ngallavan@uca.edu 